\title{
Advisory
}

\section{COVID-19 Pandemic: Advisory and Consensus Statement for the provision of surgical services from The Association of Paediatric Surgeons of Pakistan (APSP)}

\author{
Muhammad Saleem,* Nabila Talat, Imran Hashim, Muhammad Javaid Iqbal Khan, Asif Iqbal
}

Department of Pediatric Surgery, The Children's Hospital and the Institute of Child Health Lahore

\begin{abstract}
Cite as: Saleem M, Talat N, Hashim I, Khan MJI, Iqbal A. COVID-19 Pandemic: Advisory and Consensus Statement for the provision of surgical services from The Association of Paediatric Surgeons of Pakistan (APSP). J Pediatr Adolesc Surg. $2020 ; 1: 5-12$.

This is an open-access article distributed under the terms of the Creative Commons Attribution License, which permits unrestricted use, distribution, and reproduction in any medium, provided the original work is properly cited (https://creativecommons.org/ licenses/by/4.0/)
\end{abstract}

Novel Coronavirus disease (COVID-19) caused by SARSCoV-2, starting from Wuhan (China) has now spread globally affecting $12,010,593$ people all over the world with 548,057 mortality, including 237,489 cases from Pakistan including 5000 mortality till the writing of advisory.[1] The incidence in children varies between $0.8 \%$ and 3\%.[2][3][4][5] Among these, many patients need surgical interventions both emergent and elective. [6][7][8] Most of the children who contract COVID-19 infection usually remain asymptomatic, thus can spread infection unknowingly to healthcare professionals, especially during surgery. In a recent study done in USA, 12 patients turned out as COVID-19 positive among 1200 operated patients when tested for it.[6] This reflects a constant and considerable threat of transmitting the infection to the surgeons and surgical team.[9][10][11] This can result in a shortage of senior surgeons if they are continuously exposed to corona cases due to infection and quarantine.[9] As the pediatric surgical workforce is already very short in Pakistan so there is a dire need to safe it. Moreover, difficulties in the provision and use of personal protective equipment along with compromised theater conditions (not compatible with COVID-19 requirement) need guidelines and a workable plan. There is considerable morbidity and mortality of surgical interventions in patients with active COVID-19.[12][13] So, it is preferable to defer elective surgeries in such patients until the pandemic is over.[14] However operative interventions on pediatric and neonatal emergent surgical conditions like intestinal atresia, intestinal obstruction, intestinal volvulus, trauma, etc., cannot be deferred. Establishing dedicated operative facilities compatible with the requirement for surgical care of COVID-19 patients is a solution in these circumstances.

\section{Triaging surgery during COVID-19}

A committee consisting of a pediatric surgeon as lead, anesthetist, and physician dealing with COVID cases, histopathologist, and radiologist as needed pediatric oncologist or gastroenterologist should be formed. The surgical cases should be categorized into;

1. Emergency, need operation within 24 hours.

2. Emergent, need operation 24 to 72 hours

3. Semi Elective: a less than one month

4. Semi Elective: b category till 3 months and

5. Elective: More than 3 months

A detailed categorization is discussed in WOFAPS consensus statement, NHS UK, and by ACS America.[15][16][17] Following guidelines should be followed:

a) Emergency and emergent should be dealt with safely as discussed in the next section.

b) Elective surgery should not be continued until the wave of the pandemic is over and full facilities for screening and testing available.

c) Semi elective category especially oncology, and surgeries where the outcome can be changed with the passage of time like biliary atresia should be operated after getting a PCR test.[15][16]

d) Semi elective category $b$ should be deferred unless forced to do due to disease condition.

Correspondence*: Professor Dr. Muhammad Saleem, Department of Pediatric Surgery, The Children's Hospital and the Institute of 


\section{Establishing a COVID-OT}

2.1 Dedicated COVID Theater: A dedicated operating facility for COVID-19 cases having at least two operation theaters (OT) should be developed. It should be away from other non-COVID operation theatres and be labeled with clear and visible signage preferably in the local language.[18]

Location: The COVID Theater should be located near a COVID facility like Corona isolation/HDU/ICU. If it is not feasible, a part of operation theater complex, which is relatively on a side of the main theater complex and easily reachable with a minimal and straight pathway from the COVID facility, should be designated as COVIDOT.

\section{Entry/Exit, Changing Room / Donning/Doffing Area:}

COVID Theater must have separate changing rooms (with toilet and showering facility) for males and females each, and designated donning and doffing areas, which should be close to scrub sinks. It should have separate entry/exit paths and the doors of this facility can be opened with feet and elbows.

2.2 Availability of personal protective equipment (PPEs): An adequate supply of pre-sterilized PPEs along with hand sanitizers should be made available in donning areas.

2.3 Disposal of used PPEs: It should be disposed of as per the Bio-Medical Waste Management rule 2014, designed by the Government of Pakistan and CDC.[19][20][21]

\section{Heating Ventilation and Air Conditioning (HVAC) of COVID-OT}

The majority of operation theaters in Pakistan and other developing countries are either lacking any pressure gradient (usually in the periphery and private setting) or have positive pressure to prevent the ingress of virus and bacterial particles into the theater. COVID-19 situation demands a negative pressure facility to stop the spread of viral loaded particles to corridors or other ORs in order to prevent the spread of infection to other theater staff.[22][23] Moreover, in the majority of setups either split air conditioners or central air-conditioning system in use. Only a few facilities have laminar airflow systems installed in ORs.

3.1 Ideal COVID-Theater: Ideally COVID-OT should have a negative pressure with a pressure gradient of at least 5 $\mathrm{Pa}$. It should have a separate HVAC system and air handling unit (AHU) which should be away from other parts of the hospital like indoor units, outdoor units, and administration areas. If it is already connected to these units, then the ducts going to such areas should be blocked. The AHU should preferably take $100 \%$ fresh air and disposable exhaust air should be disposed of about 30 feet away from the sucking point of fresh air by AHU.[18][24] There should be an installation of HEPA filters both in the incoming air ducts and outgoing ducts.[25][26] A facility of laminar airflow in the theater provides additional protection by streamlining air in such a way that air flows from the ducts to the top of the operation table and moves to the floor (away from operation table) where it is sucked out by exhaust ducts.[15][26]

3.2 Makeshift arrangement: The theater which has a facility of split air conditioning or in which running of central air conditioning is not possible due to attachment with other non-COVID areas, those theaters can be used as follows. Two split air conditioning units ( 2 tones refrigerating capacity) can be installed in OR to circulate the air in a single room. Windows and doors should be kept minimally open so that some fresh outside air can enter the room or an exhaust fan (preferably with filter) should be applied to suck in the outside fresh air with filtration. Another exhaust fan (preferably with filter) should be applied below the level of the operating table to help in removal of stale air from OR. A portable HEPA filter (portable air purifying system) device should be placed inside the operating rooms with power of $\mathrm{H} 14$ HEPA filter.[18][25][26][27] With 20 cycles of air exchange, the viral load will be much reduced. A detailed discussion can be consulted on this topic done by the prime author on WOFAPS consensus statement.[15] With portable HEPA filter along with UVC light, even positive pressure OR can also be utilized for COVID patients safely.[15][18][26]

\section{Theater settings}

These recommendations are equally applicable to nonCOVID OTs during the pandemic.

1. Equipment in theater and its management: All unnecessary equipment, consumable items, trolleys, cabinets, and cupboards should be removed from theaters to prevent the spread of virus loaded aerosol. Assembling of any equipment should be carried outside of OR.[28]

2. All the equipment inside $\mathrm{OR}$, like anesthesia machines/workstations, cautery, suction devices, monitors, cables, should be covered with transparent impermeable plastic wrapping and this wrapping should be changed after every operation.[28][29]

3. Three trolleys, one for anesthesia drugs and equipment, second for surgical equipment, and third for linen (prepared outside of OR) are allowed to enter $\mathrm{OR}$ at appropriate times as required.

4. Try to use disposable equipment, like breathing circuits, facemasks, endotracheal tubes, cautery leads, suction nozzles, and tubes; dispose of properly after the operation.[25[29][28] If there is a need to reuse them 
then disinfect them as per $\mathrm{CDC}$ disinfection rule with appropriate disinfection agent for at least 10 minutes.[30][19]

5. Human resource management during operation: There should be a predefined minimum number of staff; one surgeon, one assistant, one nurse, one operation theatre assistant (OTA), one helping nurse, and a sanitary worker must be assigned a single OR as a surgical team. Similarly, for an anesthesia team, one anesthetist and one anesthesia technician are sufficient for one OR. A transport person and a support person should remain outside OR. OR staff should not be changed or added during operation unless deemed necessary. Similarly, one anesthetist should remain ready nearby and can be called in OR, if needed.[19]

6. During induction, surgeons and scrub nurse should stay outside of OR, and enter OR should enter OR when induction is completed and at least 3-5 cycles of air exchanges have occurred or at least 5 to 10 minutes have passed.[18][19]

\section{Screening and PCR testing before surgery}

There is still a shortage of PCR testing and free availability of PPEs till now in Pakistan and 3rd world countries. So to get PCR done before emergency/emergent surgery is still a challenge to pediatric surgeons. Resuming elective and semi elective surgery purely depends upon the facility of free availability of PCR testing. The association recommends:

1. Every patient in the category of semi elective and elective should only be operated after getting PCR testing.

2. If parents/guardians have suggested history they should also be tested.

3. If indicated X-Ray chest and HR-CT should be performed in cases with PCR positive and signs and symptoms of COVID.

4. Role immunological testing should only be supplemental to PCR as discussed in these two articles.[15][31]

5. The emergency/emergent cases should be dealt on level 4 protection if unable to get PCR as discussed in PPEs section.

\section{The decision regarding Surgical Procedures in Suspected or Confirmed COVID Patient}

The justification for performing a surgical intervention should be based on thorough history, signs, symptoms, and contact evaluation and should be discussed at length in a multidisciplinary meeting including at least 2 senior surgeons, anesthetist, parents or guardian as applicable, histopathologist, pediatric oncologist, pediatric gastroenterologist (as applicable). The final decision of a multidisciplinary team to perform a surgical procedure will not be challengeable.

\section{Personal protective equipment during COVID-19}

Regarding PPEs, guidelines provided by WHO, CDC, and local authorities should be followed.[32][33][34]

6.1 Non-tested/suspected/confirmed COVID-19 patients: A proper level 4 protection should be provided for all surgical, anesthesia, and other support staff in OR. It includes Coverall, N-95/FFP2/K-95/FFP3/N-99 respirator, goggles, face shield if needed, and long protective shoes with shoe cover.[18][28][19]

6.2 Non-COVID patients: In case of patients who are PCR negative in the last 48 hours, preferably $\mathrm{N}$ 95/FFP2/K-95 mask (can be without respirator) or if not available a double three-ply disposable surgical masks, disposable water-impermeable surgical gown, and regular OT kit should be worn.

6.3 Specification of standard PPEs: All the equipment should meet national and international standards with due certification.[18][35][19][33][36]

a) Medical/surgical/respirator mask: Like N95/FFP2/K-95 if available N-99/FFP3, (NIOSH,/EN 149FFP2, or equivalent, fluidresistant: minimum $80 \mathrm{mmHg}$ pressure tested on ASTM F1862/ISO 22609, or equivalent) be used. It should be non-collapsible, wearable with a full-face shield, and have a respirator with good breathability.

b) Coverall: A single piece, with head cover hood, compatible or higher to pressure resistance Test' (ISO 16603), resistant to permeation of biologically contaminated viral particles / body fluids/blood (ISO 22612:2005). It should be taped all around to stop fluid/blood/droplets/aerosol entry. An alternative is disposable water-impervious surgical gown along with long suit plastic sheet coverall if Tyvek suit is not available.

c) Zero power transparent Goggles/protective eyewear: Wearable with prescription glasses, having an adjustable band securing during operation, providing a seal around the eye is recommended.

d) Reusable Face shield/visor: Made of clear good quality plastic providing full-face protection on sides and length, with padded support at the forehead and comfortable elastic band is most useful. It can be cleaned/disinfected for reuse.

e) Gloves: Wear double sterile gloves

f) Show cover: Long protective shoes, extending up to mid-calf, to be used in OR which should be of the same standard as coverall.

g) Waste collection Bag 


\section{Movement of Patients suspected/confirmed cases of COVID}

Shifting Pathway: The patient should be shifted wearing N-95 or at least double three-ply surgical mask, cap, autoclave-able/disposable theater clothes, completely covered with a transparent plastic sheath, using a separate predefined pathway reserved for COVID-19 patient.[29] This pathway should be sprayed with a disinfectant just after shifting of the patient. The shifting team should wear complete PPEs of level 4 protection and obey general precautions of hand hygiene and social distances religiously.[29][35]

\section{Intraoperative management}

1. Preoperative assessment: Preoperative assessment, premedication, and documentation should be performed either in the COVID area by anesthesia personnel with level-4 PPEs, or more easily in the COVID designated OR skipping the preoperative area.[37]

2. Induction of patient: The patient should be induced in the COVID theater with full anesthetic precautions.

3. Use of Drapes for patients: During COVID-19, pandemic, regular OR dress/clothes should be avoided, and the patient is draped with water-resistant disposable drapes.

4. Recovery of the patient: The patient should be recovered in the same COVID Theater and be directly shifted back to the COVID patient area (HDU/ICU) without staying in recovery through the same defined pathway.[29]

5. Aerosol generating procedure: Aerosol generating procedures like anesthesia induction/extubation, nebulization, suctioning, high flow nasal oxygen therapy, CPAP, BiPAP, and operative procedures like bronchoscopy, esophagoscopy, colonoscopy, and laparoscopy, etc. may result in more spread of viral load in theater thus predisposing healthcare workers to the COVID-19 infection.[26][37][38] Therefore in addition to level 4 PPE, Powered Air Purifying Respirator (PAPR) should be used; alternatively, N-95/FF2/FFP3 can be used if PAPR is not available. Face shield or goggles, shoe cover, double gloves, and coverall should be used as already pointed out. PAPR is a better option, especially for respiratory aerosol-generating procedures.[35]

6. Use of unipolar, bipolar/advanced bipolar cautery, ultrasonic Harmonic scalpel, and LigaSure. These all are aerosol-generating equipment and a potential source of infection to HCW. Cautery must be used minimally with a suitable power setting to reduce the aerosol spread. High-energy devices like a harmonic scalpel and LigaSure should be attached to a smoke suction devices if available, to reduce the spread of virus-laden particles. [10][26][29][39][40][41] Monopolar diathermy pencils If available, should be attached with smoke evacuators.[39][42]

\section{Laparoscopic/endoscopic Procedures}

a) The port Incisions should be made very smart and small to prevent leakage around the port side and it should be used for smoke evacuation or desufflation during the procedure.

b) A minimum level of $\mathrm{CO} 2$ insufflation pressure should be maintained, and smoke evacuation/filtration system (ultra-filtration device) should be used to remove aerosol, $\mathrm{CO} 2$ during desufflation and pneumoperitoneum before closure or trocar removal, etc. [10][39]

c) In the absence of desufflation mode, the valve on the working port used for insufflation must be closed first to prevent backward pushing of infected $\mathrm{CO} 2$ to insufflator.[10][39]

d) The position of the patient should be flat and for desufflation the least dependent port should be used.

e) After the evacuation of smoke and $\mathrm{CO} 2$, Specimens should be removed.

f) Try to avoid surgical drains if possible.

g) The closure should be done after desufflation and should not be done with suture closure devices.

h) The smoke/aerosols should be filtered through either ULPA (ultra-low particle aspirator) or HEPA (high-efficiency particle aspirator) filter during operation. Their efficiency is $99.995 \%$ to filter virus-laden particles/aerosols. Otherwise attaching the suction apparatus to a chest drainage bottle or bag containing hypochlorite solution to disinfect it.

i) A proper multi-step approach like suitable ventilation, wearing level 4-PPEs, using ultrafiltration with smoke evacuation devices along with practicing standard safety precautions will ensure a safe atmosphere to use laparoscopy.[10][39][42]

8. Communication issue in COVID OT. It is difficult to communicate with each other wearing full PPEs, so surgical anesthesia staff should communicate with each other through sign language for quick interaction. Mobile phones and other bags and wearing's should not be allowed in COVID OT. Intercom facility or one mobile phone covered by plastic wrapping should be present in OT for outside communication.

9. The interval between operations: There should be an adequate interval of about one hour between next operation, to shift the patient as per proper protocols, disinfect the equipment, dispose of disposable items, and to disinfect the required equipment, theater, 
operating table, anesthesia machine, screens, and other equipment.[18]

10. Oxygen and logistic supply: The biogases supply and other equipment including PPEs, PAPR, drugs, gadgets, and other necessary things should be available in adequate quantity so that the operation can be completed in minimum time with minimum hindrance.

\section{OPD consultation, Pre and Post-operative care in suspected/confirmed COVID and non-COVID patients}

1. OPD and emergency consultancy should be done with all precautions as advised in international and national guidelines, at least wearing a three-ply double surgical mask, disposable gloves, and preferably disposable surgical gown/disposable plastic sheet coverall.[15][32][34]

2. Direct physical examination if possible should be avoided.

3. Telemedicine should be used for follow up cases till the pandemic is over.[43]

4. COVID-19 negative patients can be managed in surgical wards postoperatively with a mandatory assessment of temperature and respiratory system to investigate any new episode of fever or cough.

5. If develops symptoms suggestive of COVID, these patients should be strongly suspected of COVID-19 and be isolated till testing turns out negative.

6. The isolation room should be preferably negatively pressured, with sufficient oxygen supply and nebulization facility.[22][35]

7. Level-4 protection should be observed during ward rounds in strongly suspected or confirmed cases of COVID-19 with special precautionary measures to avoid contact with patients' secretions/body fluids.

8. If COVID-19 infection is confirmed or was previously identified, the medical staff involved in the care or surgery should be isolated for 14 days after the surgery.

9. In case of major surgery or critical nature of the procedure in a confirmed case of COVID-19, the patient should be managed in COVID specific HDU/ICU equipped with necessary monitoring facilities and ventilators.

10. The COVID specific areas should have all the facilities of donning/doffing and necessary PPE for the healthcare workers as indicated in the above text.

\section{Workforce management}

Surgical staff should be pooled and preferably a rotational Rota of 8 to 12 hours should be opted.

1. Emergency: Minimum staff (2 residents, one staff nurse) should be deployed in emergency triaging equipped with at least an N-95 mask, disposable sur- gical gown, surgical gloves, and head cap. One senior should do a round of emergency as required. Assessment of patients should be with full precaution and if patients having signs and symptoms of COVID should be shifted to the corona area.

2. OPD: Only one surgical unit with minimum staff should do OPD on his turn with one consultant and 2 residents till a wave of pandemic subsides wearing PPEs as discussed in the emergency section.

\section{Theater:}

a) Surgical team: For every OT a well-defined and well-rehearsed team with minimum manpower team one surgeon and one assistant, one nurse, one OTA, one sweeper should be in the OR especially COVID OT.

b) Anesthesia team: It should be opted with an anesthesia team; one anesthetist and one technician or staff nurse should be there at the induction of cases. Surgical staff should be outside OT till 3-5 cycles of air exchange have occurred or 10 minutes have passed after induction.

12. Operating table, and equipment cleaning, Decontamination, and Sterilization

1. At least one-hour interval should be observed done between two operations for cleaning, decontamination, and sterilization.[18]

2. All the disposable equipment, gloves, linen, markers, breathing circuit, draping, soda lime, surgical gauzes, sponges, masks, endotracheal tubing, HME filters, gas sampling lines, and syringes should be collected in a red bag and should be sent to incinerator facility for incineration.[19][33]

3. All unused items on anesthesia trolley, equipment trolley, and linen opened in theater, and other disposable items must be discarded and collected in a red bag for incineration.[35]

4. The reusable equipment, airway equipment, should be placed in a double zip-locked plastic bag and should be moved for decontamination, disinfection, and sterilization.

5. The metallic stainless steel equipment should be placed in $1 \%$ sodium hypochlorite solution for 30 minutes, then washed, wiped, and collected in an instrument box covered by plastic bag (clearly labeled) and sent for sterilization to the Central Sterile Supply Department (CSSD).

6. A separate dedicated area in CSSD should be reserved for sterilization of logistics from COVID OT to avoid mixing with equipment from non-COVID OT. 
7. Preferably this should be available near the COVID area or use an autoclave within the same area for sterilization.

8. Theater walls, floors, passage elevators, and hard surfaces should be decontaminated with $1 \%$ sodium hypochlorite for at least 10 minutes. The spray-able area should be sprayed with either hydrogen peroxide spray disinfection (through vaporized hydrogen peroxide generator (VHPG), or 1\% sodium hypochlorite solution, or wiping off with $75 \%$ alcohol to solid surfaces of the equipment and floor.[19][34][44]

\section{Handling Histopathological specimens}

The specimens should be immersed in 10\% buffered formalin (quantity should be 10 times for smaller, and double for bigger one). It should be collected in tight fit plastic boxes, which should be sealed in leak-proof double plastic bags. The plastic bags should be wiped clean and should be labeled properly with patient data, and clearly indicating about COVID status, before sending for examination. The form should not be handled with gloves contaminated with blood, body fluids, or any other infected material.

\section{Training of surgical staff}

A thorough and comprehensive training program regarding donning, doffing, triaging patients both in OPD and emergency, and doing rounds in wards and attending theater should be developed by the surgical team under the guidance of senior faculty as per requirement of WHO and CDC and CEAG. It should cover all human resources including surgeons, nursing staff, and paramedical staff of all surgical sections. Different online training programs are also available. Local protocols as discussed in this advisory should be practiced in the units and an audit of all processes should be conducted regularly after every week to rectify the deficiencies.

\section{Rehearsal/Mock drill}

1. Rehearsal or training should be provided to OT staff for correct donning and doffing of Personal Protective Equipment (PPE) including coverall gown, N95/FFP3/K-95 face mask, eye shields/face shields/visor, and gloves.

\section{REFERENCES}

1. Worldometer. Coronavirus Cases. Worldometer [Internet]. 2020;1-22. Available from: https://www.worldometers.info/coronavirus / coronaviruscases /\#daily-cases

2. Coronavirus Disease 2019 in Children - United States, February 12-April 2, 2020. Vol. 69, MMWR. Morbidity and mortality weekly report. 2020. p. 422-6.

3. Tagarro A, Epalza C, Santos M, Sanz-Santaeufemia FJ, Otheo E, Moraleda C, et al. Screening and Severity of
2. Mock drills of a surgical procedure from wheeling in to wheeling out of patients from operation theatre should also be practiced to get accustomed to knowing practical problems.

It is reemphasized that the cornerstone of safety is to wear masks, do regular hand washing, and maintain a physical distance.

This document is an advisory and consensus statement from APSP based on current literature, available evidence/resources, and expert opinion of pediatric surgical lead. It is apposite to mention that new evidence is continuously evolving and guidelines are being upgraded regularly.

Let's join hands with each other and work together to maintain the health of our great nation especially children and our future in Pakistan.

Disclaimer: As the information on COVID-19 is changing every day based on recent research and recommendations, therefore, these guidelines may be updated and subject to change. Neither the editorial staff of the journal nor the authors claim any responsibility in case any harm is inflicted using these guidelines. End-users must check other sources as well before using guidelines suitable to their local circumstances.

Authors Contribution: Muhammad Saleem was the main principal author of this document and have main responsibility given by APSP for the Advisory. Nabila Talat, Imran Hashim, Muhammad Javaid Iqbal Khan, and Asif Iqbal, helped in literature review and wrote few portions of the advisory. All authors have substantial contribution in writing this advisory and approved final version.

Conflict of Interest: MS, NT, IH, and AI are the members of the editorial team.

Acknowledgements: We want to acknowledge Prof. Jamshed Akhtar, who helped us in reviewing and editing of this advisory. We are also thankful of Dr. M. Bilal Mirza for reviewing and editing this advisory. We are especially grateful of Prof. Inayat ur Rehman for his trust on the team of the Children's Hospital and the Institute of Child Health, Lahore, to develop this advisory.

Coronavirus Disease 2019 (COVID-19) in Children in Madrid, Spain. JAMA Pediatrics. 2020.

4. Liu W, Zhang Q, Chen J, Xiang R, Song $\mathrm{H}$, Shu S, et al. Detection of COVID-19 in children in early january 2020 in Wuhan, China. N Engl J Med. 2020;382:1370-2.

5. Cruz AT, Zeichner ST. COVID-19 in Children: Initial Characterization of the Pediatric Disease Andrea. Pediatrics [Internet]. 2020;145:e20200834. Available from: doi: https://doi.org/10.1542/peds.2020-0834 
6. Lin EE, Blumberg TJ, Adler AC, Fazal FZ, Talwar D, Ellingsen $\mathrm{K}$, et al. Incidence of COVID-19 in Pediatric Surgical Patients Among 3 US Children's Hospitals. JAMA Surg. 2020;4-6.

7. Parikh SR, Avansino JR, Dick AA, Enriquez BK, Geiduschek JM, Martin LD, et al. Collaborative Multi-Disciplinary Incident Command at Seattle Children's Hospital for Rapid Preparatory Pediatric Surgery Countermeasures to the COVID-19 Pandemic. J Am Coll Surg. 2020;1-6.

8. Zhou Y, Xu H, Li L, Ren X. Management for patients with pediatric surgical disease during the COVID-19 epidemic. Pediatr Surg Int [Internet]. 2020;36:751-2. Available from: https://doi.org/10.1007/s00383-020-04656-6

9. Coccolini F, Perrone G, Chiarugi M, Di Marzo F, Ansaloni L, Scandroglio I, et al. Surgery in COVID-19 patients: Operational directives. World J Emerg Surg. 2020;15:1-7.

10. SAGES. Eaes and Sages Recommendations Regarding Surgical Response To COVID-19 Crisis - Eaes. 2020;1-7. Available from: https://eaes.eu/eaes-and-sagesrecommendations-regarding-surgical-response-to-COVID-19crisis/

11. American College of Surgeons. COVID 19: Considerations for Optimum Surgeon Protection Before, During, and After Operation. 2020;3-5. Available from: https://www.facs.org/COVID-19/ppe

12. Shakiba B, Irani S. COVID-19 and perioperative mortality; where do we stand? EClinicalMedicine. 2020; 22:100364.

13. Myles PS, Maswime S. Mitigating the risks of surgery during the COVID-19 pandemic. Lancet [Internet]. 2020;396:2-3. Available from: http://dx.doi.org/10.1016/S01406736(20)31256-3

14. Zarrintan S. Surgical operations during the COVID-19 outbreak: Should elective surgeries be suspended? Int J Surg [Internet]. 2020;78:5-6. Available from: https://doi.org/10.1016/j.ijsu.2020.04.005

15. Saleem M: Shehata S. WOFAPS Consensus statement: Role of the Pediatric Surgeons in COVID19. WOFAPS [Internet]. 2020;1-29. Available from:

https://www.wofaps.org/report/wofaps-consensusstatement-role-of-the-pediatric-surgeon-in-COVID19/

16. England R college of surgeons of. Clinical guide to surgical prioritisation during the coronavirus pandemic. NHS -Royal Coll Surg Engl [Internet]. 2020; Available from: https://www.england.nhs.uk/coronavirus/wp-content/uploads/sites/52/2020/03/C0221-specialty-guidesurgical-prioritisation-v1.pdf

17. ACS. COVID-19 Guidelines for Triage of pediatric Patients. ACS website [Internet]. 2020; Available from: https://www.facs.org/COVID-19/clinical-guidance/electivecase/urology

18. Malhotra N, Bajwa SJS, Joshi, M, Mehdiratta L AT. COVID Operation Theatre- Advisory and Position Statement of Indian Society of Anaesthesiologists (ISA National). Indian J Anaesth [Internet]. 2020;64:355-62. Available from: doi: 10.4103/ija.IJA_454_20

19. National Action Plan for Corona virus disease ( COVID-19) Pakistan. Minist Natl Heal Serv Regul Coord Gov Pakistan [Internet]. 2020;1-136. Available from: https://app.adpc.net/index.php/publications / nationalaction-plan-coronavirus-disease-COVID-19-pakistan

20. CDC. Coronavirus Disease 2019 (COVID-19) Information for Healthcare Professionals. March 26, 2020 [Internet]. 2020;2019. Available from: https://www.cdc.gov/coronavirus / 2019ncov/hcp/index.html

21. Punjab EP depatment G of. Punjab Hospital Waste Management Rules, 2014_0.pdf. Punjab Wkly Gaz July 30, 2014 [Internet]. 2014;2:1-14. Available from: https://epd.punjab.gov.pk/system/files/Punjab\%2520Hospi tal\%2520Waste $\% 2520$ Management $\% 252$
22. Chow TT, Kwan A, Lin Z, Bai W. Conversion of operating theatre from positive to negative pressure environment. J Hosp Infect. 2006;64(4):371-8.

23. Dexter F, Parra MC, Brown JR, Loftus RW. Perioperative COVID-19 Defense: An Evidence-Based Approach for Optimization of Infection Control and Operating Room Management. Anesthesia and analgesia. 2020.

24. Sánchez-Barroso G, Sanz-Calcedo JG. Evaluation of HVAC design parameters in high-performance hospital operating theatres. Sustain. 2019;11:1493-1506.

25. Christopherson D, Yao WC, Lu M, Vijayakumar R, Sedaghat $R$, Surgery N, et al. High-efficiency particulate air ( HEPA ) filters in the era of COVID-19: function and efficacy. Otolaryngol Neck Surg [Internet]. 2020; Available from: https://www.google.com/url

26. Parvizi J, Gehrke T, Krueger CA, Chisari E, Citak M, Van Onsem S, et al. Resuming Elective Orthopaedic Surgery During the COVID-19 Pandemic: Guidelines Developed by the International Consensus Group (ICM). J bone Jt surgery $\backslash .2020 ;(\mathrm{Icm}): 1-43$.

27. ENVIRCO. Low to High Clean Air Circulation Pattern. Fedders Engeering Prod [Internet]. 2020;10-1. Available from: www.envirco.com

28. Wong J, Goh QY, Tan Z, Lie SA, Tay YC, Ng SY, et al. Preparing for a COVID-19 pandemic: a review of operating room outbreak response measures in a large tertiary hospital in Singapore. Can J Anesth [Internet]. 2020;67:732-45. Available from: https://doi.org/10.1007/s12630-02001620-9

29. Lie SA, Wong SW, Wong LT, Wong TGL, Chong SY. Practical considerations for performing regional anesthesia: lessons learned from the COVID-19 pandemic. Can J Anesth [Internet]. 2020; Available from: https://doi.org/10.1007/s12630-020-01637-0

30. CDC. Coronavirus Disease 2019 (COVID-19): Interim Infection Prevention and Control Recommendations. Cent Dis Control Prev [Internet]. 2020;2:1-11. Available from: https://www.cdc.gov/coronavirus/2019-ncov/infectioncontrol/control-recommendations.html

31. Al-Muharraqi MA. Testing recommendation for COVID-19 (SARS-CoV-2) in patients planned for surgery - continuing the service and 'suppressing' the pandemic. $\mathrm{Br} \mathrm{J}$ Oral Maxillofac Surg. 2020.

32. World Health Organization (WHO). Rational use of personal protective equipment for coronavirus disease 2019 (COVID19) and considerations during severe shortages. WHO [Internet]. 2020;2019:1-28. Available from: https://apps.who.int/iris/handle/10665/331695

33. Center for Disease Control and Prevention. Interim Infection Prevention and Control Recommendations for Patients with Suspected or Confirmed Coronavirus Disease 2019 (COVID19) in Healthcare Settings. Cdc [Internet]. 2020;2:1-10. Available from: https://www.cdc.gov/coronavirus/2019ncov/infection-control/control-recommendations.html

34. Sadiq M, Saleem M, Alvi MY, Junaid RashidJ BA. Hand Book of Pediatric COVID-19 and standard Operating Procedure. Hand B Pediatr COVID-19. 2020;2:1-64.

35. Lee-Archer $P$, von Ungern-Sternberg BS. Paediatric Anaesthetic implications of COVID-19 - A Review of Current Literature. Pediatr Anesth. 2020:1-6.

36. ANZCA. Clinical resources - Coronavirus:COVID-19 resources - Library guides at Australian and New Zealand C. ANZCA Libr clincial Resour [Internet]. 2020; Available from: https://libguides.anzca.edu.au/COVID-19

37. Ti LK, Ang LS, Foong TW, Ng BSW. What we do when a COVID-19 patient needs an operation: operating room preparation and guidance. Can J Anesth [Internet]. 2020;1921. Available from: https://doi.org/10.1007/s12630-020$01617-4$

38. Tran K, Cimon K, Severn M, Pessoa-Silva CL, Conly J. Aerosol generating procedures and risk of transmission of 
acute respiratory infections to healthcare workers: A systematic review. PLoS One. 2012;7.

39. SAGES. Resources for Smoke \& Gas Evacuation During Open, Laparoscopic, and Endoscopic Procedures - SAGES. SAGES Webmaster [Internet]. 2020;1-7. Available from: https://www.sages.org/resources-smoke-gas-evacuationduring-open-laparoscopic-endoscopic-procedures /

40. Li CI, Pai JY, Chen CH. Characterization of smoke generated during the use of surgical knife in laparotomy surgeries. Vol. 70 , Journal of the Air and Waste Management Association. 2020. p. 324-32.

41. Li CI, Pai JY, Chen CH. Characterization of smoke generated during the use of surgical knife in laparotomy surgeries. J Air Waste Manag Assoc [Internet]. 2020;70:324-32. Available from: http:/ / dx.doi.org/10.1080/10962247.2020.1717675
42. SAGES. COVID -19, Medical Device Repository [Internet]. SAGES Webmaster. 2020. p. 1-5. Available from: https://www.sages.org/resources-smoke-gas- evacuationduring-open-laparoscopic-endoscopic- procedures/)

43. Hirschmann MT, Hart A, Henckel J, Sadoghi P, Seil R, Mouton C. COVID-19 coronavirus: recommended personal protective equipment for the orthopaedic and trauma surgeon. Knee Surgery, Sport Traumatol Arthrosc [Internet]. 2020;(0123456789):1-9. Available from: http://link.springer.com/10.1007/s00167-020-06022-4

44.EPA. List N: Products with Emerging Viral Pathogens AND Human Coronavirus claims for use against SARS-CoV-2. Environ Prot Agency [Internet]. 2020;1-38. Available from: https://www.epa.gov/pesticide-registration/list-ndisinfectants-use-against-sars-cov-2-COVID- 